\title{
Outcome of Cemented Bipolar as Primary Management of Comminuted Unstable Intertrochanteric Fracture Femur in Elderly Sudanese Patients
}

\author{
Ammar Hassan Abdelgadir ${ }^{1}$, Mohamed Hamid Awadelsied ${ }^{2}$, Emadeldin Mustafa Elbushra $^{3}$, \\ Yasir Noureldaim Gashi, \\ ${ }^{1}$ Orthopedics, Khartoum Teaching Hospital, Sudan \\ ${ }^{2}$ Orthopedic Fellowship, Khartoum Teaching Hospital, Sudan \\ ${ }^{3}$ Orthopedic Consult, Best Care Hospital, Sudan \\ ${ }^{4}$ Department of Orthopedics, Khartoum University, Khartoum Teaching Hospital, Sudan
}

Copyright $\bigcirc 2016$ by authors, all rights reserved. Authors agree that this article remains permanently open access under the terms of the Creative Commons Attribution License 4.0 International License

\begin{abstract}
Unstable intertrochanteric fractures in osteoporotic bones of elderly patients was a real challenge that face orthopedic surgeon because of difficult anatomical reduction, poor bone quality and complication of prolonged bed redden or limited ambulation. The aim of study was to assess the clinical outcome of cemented bipolar as primary management of comminuted intertrochanteric fracture femur in elderly Sudanese patients. Material and methods: (30) Elderly Sudanese patients with unstable intertrochanteric fractures (kyle type III or IV) treated by primary hemiarthroplasty using a cemented bipolar prosthesis. Suture or wire fixations were used for reconstruction of greater trochanter fracture. Harris hip score was used for the clinical evaluation. Result: There was a significant relation between age and kyle classification ( $\mathrm{p}$ value 0.05). According to Harries hip score 17 out of 30 had a good to excellent result $(56.7 \%)$ If the patients with a fair result were also included, the percentage goes up to (93.4\%). Conclusion: The primary cemented bipolar hemiarthroplasty in unstable intertrochanteric fracture in elderly patients' dose provide staple, pain free with early mobilization, better range of motion and less complication rate in short term follow up.
\end{abstract}

Keywords Primary Hemiarthroplasty, Unstable Intertrochanteric Fractures, Primary Cemented Bipolar

\section{Introduction}

Intertrochanteric fractures were a major cause of disability and death in the elderly. The incidence of all hip fractures is approximately 80 per 100,000 persons and is expected to double over the next 50 years as the population,
Intertrochanteric fractures make up $45 \%$ of all hip fractures[6].

Stable fractures can be easily treated with osteosynthesis with predictable results. However, the management of unstable intertrochanteric fractures (Evans type III or IV and AO/OTA type 31-A2.2 and 2.3) [3, 8] in elderly patients is a challenge because of the difficulty in obtaining anatomical reduction, it was associated with high rates of morbidity and mortality, although the results have improved with the use of internal fixation. In these patients however, comminution, osteoporosis, and instability often preclude the early resumption of full weight bearing. Treatment with primary bipolar arthroplasty rather than internal fixation could perhaps return these patients to their pre-injury level of activity more quickly, thus obviating the postoperative complications caused by immobilization or failure of the implant.

The most often used classification system for intertrochanteric fractures is based on the stability of the fracture pattern and the ease in achieving a stable reduction. This classification was introduced by Evans in 1949 and accurately differentiates stable fractures (standard oblique fracture pattern) from unstable fractures (reverse oblique fracture pattern). It is important to identify a reverse oblique fracture because this type of fracture should not be treated with a standard compression plate. The stability of intertrochanteric fractures depends on the integrity of the posteromedial cortex, and instability increases with comminution of the fracture, extension of the fracture into the subtrochanteric region, and the presence of a reverse oblique fracture pattern [11]

The importance of fracture pattern is detailed in the classification by Kyle (1994) which distinguishes four basic patterns that reflect increasing instability and increasing difficulty at reduction and fixation. 
Type 1: Undisplaced uncomminuted

Type2: Displaced minimal comminution (Lesser trochanter fracture) and varus deformity.

Type3: Displaced Comminuted (Greater trochanter and lesser trochanter fracture) and varus deformity.

Type4: Severely comminuted with Subtrochanter extension (Also reverse oblique) [7].

The various treatment options for intertrochanteric fractures are operative. The non-operative method used to be treatment of choice in early 19th century when operative technique was not evolved enough to do stable fixation. Non operative treatment should only be considered in non-ambulatory or chronic dementia patients with pain that is controllable with analgesics and rest, terminal diseases with less than 6 weeks of life expectancy, unresolved medical comorbidities that preclude surgical treatment, active infectious diseases that itself a contraindication for insertion of a surgical implant and incomplete pertrochanteric fractures diagnosed by MRI. Non operative approach includes reduction via traction and early mobilization within the limits of pain tolerance [9].

The conservative approach has a high complication rate. The common problems of prolonged immobilization, decubitus ulcers, urinary tract infection (U.T.I), joint contractures, pneumonia, and thromboembolism contribute to the high mortality rate, increased incidence of varus deformity and shortening results in poor function [9].

The operative management of intertrochanteric fractures has evolved since usage of fixed nail plate, dynamic hip screws [9]. The primary reason for surgery is to allow for early mobilization of the patient, with partial weight-bearing restrictions depending on the stability of the reduction.

\section{Material and Methods}

This was a prospective hospital based study done at Best care hospital in Khartoum city at Allamab.

The operations were done by lateral approach in decubitus position and use The LINKSP II hip prosthesis stem the greater trochanteric reconstructed either with suture or wire cerclage. Study was conducted over a period from January 2014 to February 2015.All patients presented with unstable intertrochanteric fracture

Inclusion criteria: Patients diagnosed as unstable intertrochanteric fracture kyle (type 3 and 4), Age above 60 years

Exclusion criteria: Patient presented with multiple fractures or with pathological fracture

The study was analyzed using statistical package for social science (SPSS) version19.

\section{Results}

The total number of patients enrolled in this study was (30) patients. All of them underwent primary cemented hemiarthroplasty to manage unstable intertrochanteric fracture. Most of patients were 70 years or greater (17) patients .The majority were a female patients (Figure 1).

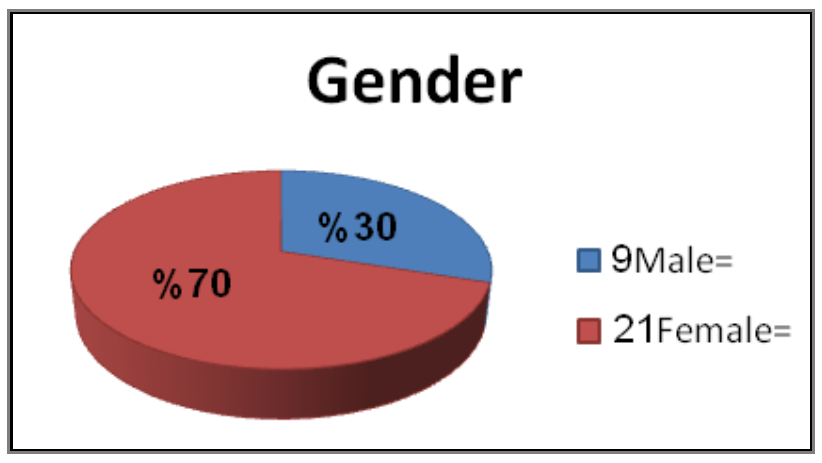

Figure 1. Shows distribution of patients according to gender

Most of patients presented early in the first week (83.3\%) patients with few exceptions whom presented late.

Duration of surgery varies between $1-2$ hours per patient.

According to kyle classification (56.7\%) of patients were type three (figure 2).

\section{Kyle classification}

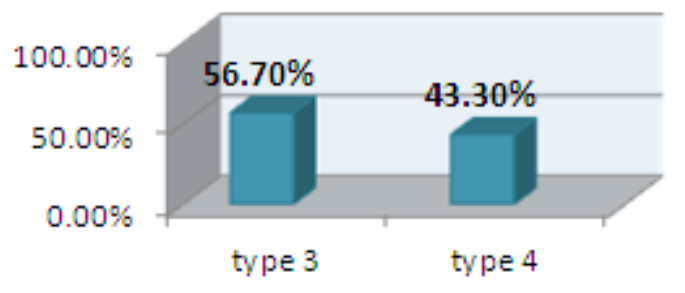

Figure 2. Shows classification of the fracture according to kyle classification

Concerning the comorbidity (12) patients have diabetes mellitus two of them had also asthma.

Regarding amount of blood loss during operation (16) patients had blood loss less than $500 \mathrm{ml}$ (figure3).

\section{Blood loss}

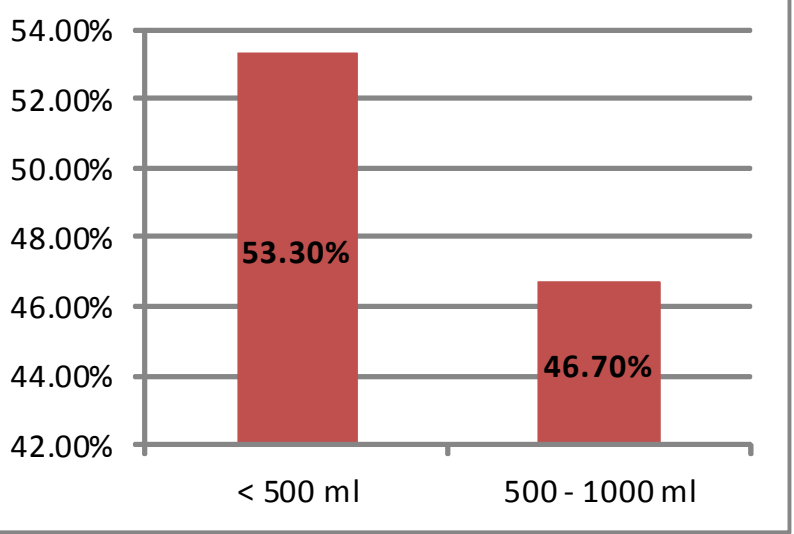

Figure 3. Show the amount of blood loss during the operation 
Six patients stay at hospital for three days but the majority of patient stay for about $(4-7)$ days (figure 4$)$.

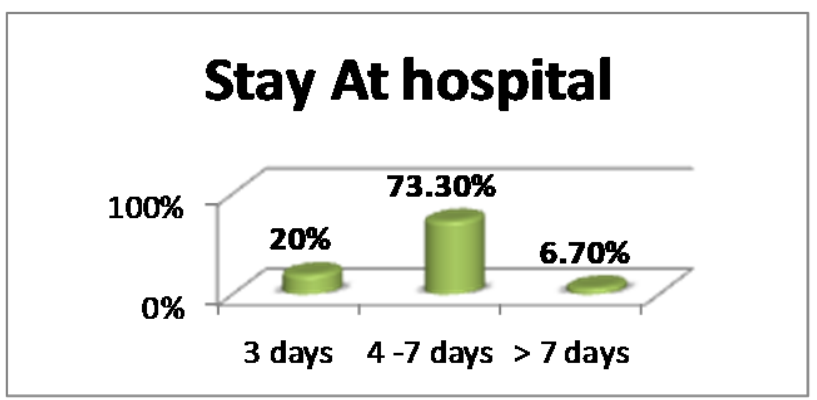

Figure 4. Shows the time of stay at hospital

Regarding mobilization at bed all the thirty patients start mobilization immediately in the same day of operation (table $1)$.

Table 1. Show Mobilization of patients at bed

\begin{tabular}{|c|c|c|}
\hline Mobilization at bed & frequency & Percent \\
\hline Immediately & 30 & $100 \%$ \\
\hline $1^{\text {st }}$ day post operation & 0 & $00.0 \%$ \\
\hline $2^{\text {nd }}$ day post operation & 0 & $00.0 \%$ \\
\hline$>2^{\text {nd }}$ day post operation & 0 & $00.0 \%$ \\
\hline Total & 30 & $100 \%$ \\
\hline
\end{tabular}

Concerning partial weight bearing most of patients ( 28 ) start partial weight bearing in the first day post-operative and few of them need more than two days to start partial weight bearing ( figure 5 ).

\section{Partial wt bearing}

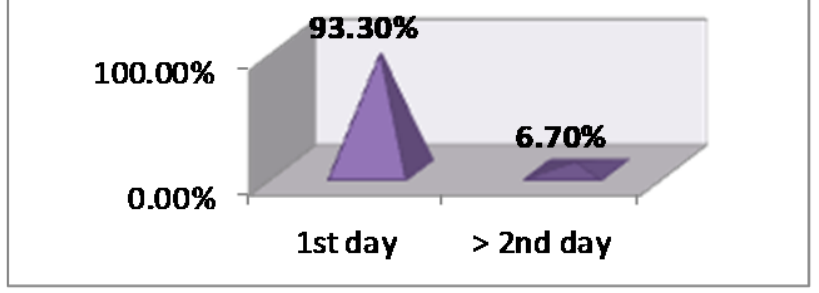

Figure 5. Shows the time of starting partial weight bearing

Regarding full weight bearing ( 28 ) patients start full weight bearing while using Zimmer frame in the first post-operative day while two patient need more than two days to start full weight bearing.

Only one patient developed post-operative infection and no patient had neither peri-prosthetic fracture, nor prosthetic dislocation.

The pain is subsided in (28) patients while the other patients had slight to mild pain (figure 6).

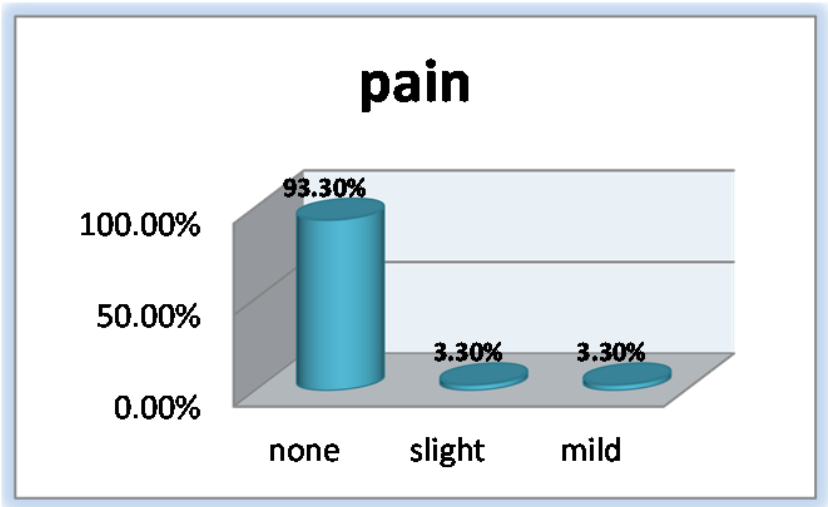

Figure 6. Shows the distribution of patients according to felling of pain at follow up

Regarding the range of motion all the thirty patients had excellent range of motion.

According to Harris hip score the patient with excellent and good outcome were ( 17 )patients and the rest of patients were fair to poor outcome ( table 2 ).

Table 2. Show Total Harris Hip Score (mean follow up 6 month)

\begin{tabular}{|c|c|c|c|}
\hline \multicolumn{2}{|c|}{ Total Harris hip score } & frequency & percent \\
\hline Excellent & $90-100$ & 3 & $10 \%$ \\
\hline Good & $80-89$ & 14 & $46.7 \%$ \\
\hline Fair & $70-79$ & 11 & $36.7 \%$ \\
\hline Poor & $<70$ & 2 & $6.7 \%$ \\
\hline \multicolumn{2}{|c|}{ Total } & 30 & $100 \%$ \\
\hline
\end{tabular}

There is a significant relation between age and classification, (kyle type four is more common in patients above 70 years). Patients above 70 years had blood loss more than patient below 70 years, But it does not affect neither pain ( Patients above 70 years had no pain more than that in patients below 70 years ) nor the mobilization of the patient in the bed, outcome of harris hip score in both age group table (3).

Table 3. Show the relation between age and harris hip score

\begin{tabular}{|c|c|c|c|c|c|}
\hline \multirow{2}{*}{ Age } & \multicolumn{4}{|c|}{ Total Harris Hip Score } & \multirow{2}{*}{ Total } \\
\cline { 2 - 5 } & Excellent & Good & Fair & poor & \\
\cline { 2 - 5 } & $90-100$ & $80-89$ & $70-79$ & $<70$ & \\
\hline $60-70 \mathrm{yr}$ & 1 & 7 & 4 & 1 & 13 \\
\hline$>70 \mathrm{yr}$ & 2 & 7 & 7 & 1 & 17 \\
\hline Total & 3 & 14 & 11 & 2 & 30 \\
\hline
\end{tabular}

P value : 0.890

Both Kyle type three and four were more common in females than in males. Two females had mild pain ( may require aspirin ). Gender doesn't affect partial weight bearing neither the total outcome according to Harris hip score. 
Kyle classification didn't affect the pain outcome in our study. And Kyle Type three had excellent and good outcome while type four had fair and poor outcome table (4).

Table 4. Show relation between kyle classification and Harris Hip Score

\begin{tabular}{|c|c|c|c|}
\hline \multirow{2}{*}{ Kyle classification } & \multicolumn{2}{|c|}{ Harris hip score } & \multirow{2}{*}{ Total } \\
\cline { 2 - 3 } & $\begin{array}{c}\text { Excellent and } \\
\text { good }\end{array}$ & $\begin{array}{c}\text { Faire and } \\
\text { poor }\end{array}$ & \\
\hline Type 3 & 11 & 6 & 17 \\
\hline Type 4 & 6 & 7 & 13 \\
\hline Total & 17 & 13 & 30 \\
\hline
\end{tabular}

P value: 0.789

The majority of the patients who presented after the first week had more blood loss during surgery.

Time of presentation had no effect in final outcome in study.

The patients with no comorbidity had best outcome in Harris hip score table.

\section{Discussion}

Management of unstable intertrochantric fracture is real challenge for orthopedic surgeon despite modern methods of osteosynthesis, early mobilization is still avoided in cases with comminution, diminished bone stock or poor screw fixation. Hence, primary hemiarthroplasty has been used as an alternative for unstable intertrochantric fractures since 1971, allowing early mobilization in these patients and preventing postoperative complications [12-5]. Tronzo [13] claimed to be the first to use long straight stemmed prosthesis for the primary treatment of intertrochantric fracture. Rosenfeld et al.[10] reported good results with the use of the Leinbach prosthesis. Since then, there have been multiple studies showing good results using this technique [4]. The earliest comparison of internal fixation and hemiarthroplasty was perform by Haentjens et al. ${ }^{9}$ showing significant reduction in the incidence of pneumonia and pressure sore in those undergoing prosthesis replacement. In comparative study on cone hemiarthroplasty versus internal fixation, Kayali et al.[2] reached the conclusion that clinical result of both group were similar. Hemiarthroplasty patients were allowed full weight bearing significantly earlier than the internal fixation patients. Broos et al. [1] concluded the operative time, blood loss and mortality rates were comparable between the two groups, with slightly higher percentage (73 versus $63 \%$ ) in those receiving prosthesis. The functional outcome was comparable between both groups. The results of the present study are comparable with and supporting the above results, despite using different types of prostheses and different surgical approaches. Cemented bipolar hemiarthroplasty was used in this study because of its low price. the lateral approach was preferred because of its shorter operative time, less blood loss and lower incidence of postoperative dislocation also several studies have shown no difference in mortality between the

internal fixation and arthroplasty groups[1].

\section{Conclusions}

In the elderly, unstable intertrochantric fractures with osteoporosis or comminution could be effectively managed by cemented bipolar hemiarthroplasty, allowing mobilization with a stable, pain free and mobile joint with acceptable complication rate.

\section{Recommendation}

We recommend

1. To consider cemented hemiarthroplasty as an alternative option in the management of unstable intertrochanteric fractures in the elderly.

2. More studies with bigger sample size and longer duration are needed in the future.

3. More comparative studies with other modalities of management are also recommended.

\section{Questionnaire of Outcome of Bipolar as Primary Management of Comminuted Fracture Neck of Femur in Elderly}

\section{1- Age \\ $1-\square 60-70$ \\ 2-Sex \\ 1- $\square$ Male}

3-Time of surgery

$1-\square 1$ st week

3- $\square$ 3rd week

\section{4-Duration of surgery}

1 - $\square$ less than $1 \mathrm{hr}$

3- $\square$ more than $2 \mathrm{hrs}$

5- Classification (kyle)

$1-\square$ type 1

3- $\square$ type 3

6- Comorbidity

1- $\square$ Diabetes mallets

3- $\square$ use steroid drugs

\section{7- Blood loss}

1- $\square$ Less than $500 \mathrm{ml}$

3- $\square$ More than $1000 \mathrm{ml}$

8-Stay at hospital

1- $\square 3$ days

3- $\square$ More than 7day

9- Mobilization at bed

1- $\square$ Immediately

3- $\square$ 2nd day post operation
2- $\square$ More than 70

2- $\square$ Female

2- $\square$ 2nd week

4- $\square$ More than 3 weeks

2- $\square 1-2 \mathrm{hr}$

2- $\square$ type 2

4- $\square$ type 4

2- $\square$ asthma

4- $\square$ none

2- $\square 500-1000 \mathrm{ml}$

2- $\square 4-7$ days

2- $\square$ 1st day post operation 4- $\square$ more than 2nd day 


\author{
10- Partial weight bearing \\ 1- $\square$ Immediately \\ 3- $\square$ 2nd day post operation
}

2- $\square$ 1st day post operation

11- Full weight bearing

1- $\square$ Immediately

3- $\square$ 2nd day post operation

\section{2-Prosthetic infection}

$1-\square$ Yes

13-Peri prosthetic fracture

$1-\square$ Yes

14-Prosthetic dislocation

$1-\square$ Yes
2- $\square$ with difficulty (2)

3- $\square$ Unable (0)

23-Absence of Deformity (All yes $=4$; Less than $4=0$ )

Less than $30^{\circ}$ fixed flexion contracture $\square$ Yes $\square$ No

Less than $10^{\circ}$ fixed abduction $\square$ Yes $\square$ No

Less than $10^{\circ}$ fixed internal rotation in extension

$\square$ Yes $\square$ No

Limb length discrepancy less than $3.2 \mathrm{~cm} \square$ Yes $\square$ No

\section{4-Range of Motion (*indicates normal)}

Flexion $\left(* 140^{\circ}\right)$

Abduction $\left(* 40^{\circ}\right)$

Adduction $\left(* 40^{\circ}\right)$

External Rotation $\left(* 40^{\circ}\right)$

Internal Rotation $\left(* 40^{\circ}\right)$

Range of Motion Scale

$\begin{array}{ll}211^{\circ}-300^{\circ}(5) & 61^{\circ}-100(2) \\ 161^{\circ}-210^{\circ}(4) & 31^{\circ}-60^{\circ}(1) \\ 101^{\circ}-160^{\circ}(3) & 0^{\circ}-30^{\circ}(0)\end{array}$

Range of Motion Score

\section{5-Total Harris Hip Score}

1- $\square$ Excellent (100 - 90)

3- $\square$ Fair (79-70)

2- $\square$ Good (89-80)

4- $\square$ Poor $(<70)$

5- $\square$ Marked pain, serious limitation of activities (10)

6- $\square$ Totally disabled, crippled, pain in bed, bedridden (0)

16- Limp

1- $\square$ None (11) 2- $\square$ Slight (8)

3- $\square$ Moderate (5) 4- $\square$ Severe (0)

\section{7-Support}

1- $\square$ None (11)

2- $\square$ Cane for long walks (7)

3- $\square$ Cane most of time (5)

4- $\square$ One crutch (3)

5- $\square$ Two canes (2)

6- $\square$ Two crutches or not able to walk (0)

\section{8-Distance Walked}

1- $\square$ Unlimited (11)

2- $\square$ Six blocks (8)

3- $\square$ Two or three blocks (5)

4- $\square$ Indoors only (2)

5- $\square$ Bed and chair only (0)

\section{9-Sitting}

1- $\square$ Comfortably in ordinary chair for one hour (5)

2- $\square$ On a high chair for 30 minutes (3)

3- $\square$ Unable to sit comfortably in any chair (0)

\section{0-Enter public transportation}

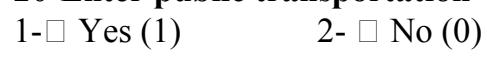

\section{1-Stairs}

1- $\square$ Normally without using a railing (4)

2- $\square$ Normally using a railing (2)

3- $\square$ In any manner (1)

4- $\square$ Unable to do stairs (0)

\section{2-Put on Shoes and Socks}

$1-\square$ with ease (4)

\section{REFERENCES}

[1] Broos PL, Rommens PM, Deleyn PR, Geens VR, Stappaerts $\mathrm{KH}$. Pertrochanteric fracture in elderly: are there indications for primary prosthetic replacement? J Orthop Truma 1991; 5:446-451.

[2] C Kayali, H Agus, S Ozluk, C Sanli. Treatment for unstable intertrochanteric fractures in elderly patients: internal fixation versus cone hemiarthroplasty. Journal of Orthopaedic Surgery 2006; 14(3):240-4.

[3] Evans EM. The treatment of trochanteric fractures of the femur. J Bone Joint SurgAm1949; 3 1: 190-203.

[4] Grimsrud C, Monzon RJ, Richman J, Ries MD. Cemented hip arthroplasty with a novel cerclage cable technique for unstable intertrochantric fractures. J Arthroplasty 2005; 20: 337-343.

[5] Haentjens P, Casteleyn PP, De Boeck H, Handlberg F, Opdecam P. treatment of unstable intertrochantric and Subtrochanteric fracture in elderly patients. Primary bipolar hemiarthroplasty compared with internal fixation. J Bone Joint Surgery Am 1989; 71:1214-1225.

[6] JD Zuckerman: Hip fracture. NEngl J Med 1996; 334:1519-1523.

[7] Kyle RF. Fractures of the Proximal Part of the Femur. JBoneJoint Surg1994; 76A: 924-50.

[8] Marsh JL, Slongo TF, Agel J, Broderick JS, Creevey W, De Coster TA, et al. Fracture and dislocation classification compendium: Orthopaedic Trauma Association classification, database and outcomes committee. J OrthopTrauma 2007; 21:S1-133.

[9] Ranjeetesh Kumar, R.N. Singh, and B.N. Singh, Comparative 
prospective study of proximal femoral nail and dynamic hip screw in treatment of intertrochanteric fracture femur.

[10] Rosenfeld RT, Schwartz DR, Alter AH. Prosthetic replacement for trochanteric fracture of the femur. J Bone Joint Surg Am 1973; 55:420.

[11] Rosen JE. Chen FS. Hiebert R Koval KJ. Efficacy of preoperative skin traction in hip fracture patients: a prospective, randomized study. J Orthop Trauma 2001; 15:
$81-5$.

[12] Stem MB, Angerman A. Comminuted intertrochantric fractures treated with a leinbach prosthesis. Clin Orthop Relat Res 1987; 218: 75-80.

[13] Tornzo RG. The use of an endoprosthesis for severely intertrochantric fracture. Orthop Clin North Am 1974; 5: 679-681. 